\title{
Laparoscopic repair of giant hiatal hernia: a narrative review
}

\author{
Amit Bhargava, Rafael Andrade \\ Division of Thoracic and Foregut Surgery, Department of Surgery, University of Minnesota, Minneapolis, MN, USA \\ Contributions: (I) Conception and design: All authors; (II) Administrative support: A Bhargava; (III) Provision of study materials or patients: \\ A Bhargava; (IV) Collection and assembly of data: A Bhargava; (V) Data analysis and interpretation: All authors; (VI) Manuscript writing: All \\ authors; (VII) Final approval of manuscript: All authors. \\ Correspondence to: Amit Bhargava, MD. Division of Thoracic and Foregut Surgery, Department of Surgery, University of Minnesota, 420 Delaware \\ St. SE, MMC 207, Minneapolis, MN 55455, USA. Email: bharg041@umn.edu.
}

\begin{abstract}
Laparoscopic repair of giant hiatal hernia $(\mathrm{GHH})$ is the current standard of care. The basic tenets of the operation are reduction of hernia sac and herniated contents with extensive mediastinal dissection, to obtain at least 2 to $3 \mathrm{~cm}$ of intra-abdominal esophagus after reduction; tension-free closure of the hiatus; preservation of the vagus nerves; and fundoplication based on individual patient characteristics. If the esophagus is short after reduction and extensive mediastinal mobilization, i.e., less than 2 to $3 \mathrm{~cm}$ of intraabdominal esophagus, then a lengthening procedure is required. Although there is some general agreement on the basic tenets of the operation, several concepts have defied definition to date. The definition of a "giant" hiatal hernia is imprecise. The determination of recurrence remains unsettled. Many surgeons still use mesh reinforcement of hiatal closure despite evidence that does not support its use. Most surgeons would probably agree that operating on a patient with a symptomatic $\mathrm{GHH}$ is indicated, there is less concordance about how to treat truly asymptomatic or minimally symptomatic patients. This paper reviews the current state of laparoscopic repair of GHH and describes the authors' approach to management of GHH.
\end{abstract}

Keywords: Hiatal hernia; laparoscopy; giant hiatal hernia (GHH); review

Received: 21 February 2020; Accepted: 13 November 2020; Published: 10 July 2021.

doi: $10.21037 /$ shc-20-50

View this article at: http://dx.doi.org/10.21037/shc-20-50

\section{Introduction}

In the 100 years since Soresi performed the first operation to reduce a hiatal hernia and approximate the crura in 1919 via laparotomy, laparoscopic repair of giant hiatal hernia $(\mathrm{GHH})$ has become the standard of care (1). Over this period, our understanding of GHH and the surgical techniques used to treat them has progressed. In 1956 Nissen described a fundoplication technique that we still use with minor modifications (2). One year later, Collis described the technique of transthoracic gastroplasty to treat short esophagus (3). Skinner showed the importance of the intraabdominal esophagus as part of the antireflux valve. This led to the current rationale for surgery of a tension-free reduction of the distal esophagus in patients with hiatal hernia. Skinner reported that the shortened esophagus is related to high recurrence rates of hiatal hernia after repair (4). Only recently, some twenty years ago, Maziak et al. published the first modern report of open transthoracic surgical GHH repair with routine Collis gastroplasty and fundoplication (5). That same year, Johnson et al. published a report of a completely laparoscopic hernia reduction with Collis gastroplasty and Nissen fundoplication (6). Over time and with strict adherence to the principles of tension-free hiatal hernia repair, laparoscopic repair of GHH became the standard of care. Several studies have shown shorter hospital stays and reduced perioperative complications, but similar longterm outcomes when compared to open techniques (710). Robotic-assisted GHH repair has also gained some popularity over the past 20 years (11-13), but is not in widespread use at this time and is conceptually the same as laparoscopic repair. Although open transabdominal and transthoracic approaches are still in use, surgeons at high- 
volume centers only use these approaches for a very small minority of patients when a minimally invasive approach is not feasible. We present the following article in accordance with the NARRATIVE REVIEW reporting checklist (available at http://dx.doi.org/10.21037/shc-20-50).

\section{Definition of GHH}

The definition of hiatal hernia is well established. A type I hernia is a pure sliding hernia; a type II hernia is a true paraesophageal hernia with minimal or not cephalad displacement of the GEJ and is very rare; a type III hiatal hernia is a combination of a sliding and a paraesophageal hernia; and a type IV hiatal hernia includes stomach as well as other intra-abdominal organs (e.g., colon, small bowel, spleen). We do not use the term giant "paraesophageal" hernia because it can create confusion. Type II true paraesophageal hernias generally are quite symptomatic and patients tend to present before these hernias are very large.

There is no consensus on what a "giant" hiatal hernia is, the definition sometimes includes $30 \%$ of stomach and other times $50 \%$ of stomach. Intragastric volume and position are in constant flux, depending on a multitude of factors and determining what percent of a hollow viscus is herniated into the chest can be quite difficult. Generally, $\mathrm{GHH}$ are type III or type IV hiatal hernias.

In summary, the definition of $\mathrm{GHH}$ is cephalad displacement of $30 \%$ to $50 \%$ of the stomach through the diaphragmatic hiatus and is commonly a type III or IV hiatal hernia.

\section{GHH presentation}

Patients with GHH commonly have dysphagia, chest pain, and postprandial retrosternal and epigastric fullness. Heartburn and regurgitation also occur frequently. Careful questioning can reveal that over the years, patients first presented with typical GERD symptoms and eventually evolved to obstructive symptoms. The transition from predominantly GERD symptomatology to obstructive symptomatology tends to occur in patients with type III GHH. Some patients minimize their obstructive symptoms because they have been symptomatic for many years, however, further inquiry can reveal that they eat very slowly and only small amounts at a time.

Other presentations include dyspnea from very large hernias, aspiration and pneumonia, and anemia with or without endoscopic evidence of mucosal abnormalities (i.e.,
Cameron ulcers).

\section{Workup of GHH}

Patients with GHH often have carried the diagnosis for many years or receive the diagnosis after a work up for chest pain with a chest X-ray or a CT scan. Proper evaluation of a $\mathrm{GHH}$ requires esophagram or chest CT scan, endoscopy, hemoglobin, and if indicated, albumin and prealbumin. Manometry is often unsuccessful because the catheter cannot pass the LES, 24-h pH test does not add value and does not guide the decision for a fundoplication in this group of patients, and gastric emptying is misleading because of retention above the diaphragm. We individualize the need for pulmonary function tests if warranted by history or radiologic findings (14).

\section{Indications for surgical treatment of GHH}

\section{Symptomatic patients}

Patients with symptomatic, non-strangulated GHH can undergo surgery electively at any time. However, patients with a crescendo pattern of worsening symptoms over several weeks must undergo surgery soon to prevent incarceration. We individualize the timing of surgery based on symptoms and other patient factors. Two studies have attempted to provide evidence in favor of surgical intervention in patients with GHH. In 1967, Skinner observed that out of 21 patients with type II hernias who were treated medically, there was a mortality rate of $29 \%$. Therefore, he recommended surgery in all patients with type II hernias, regardless of symptoms, if there were otherwise no contraindications to surgery (4). The main caveat of this study is that surgical and medical care have evolved significantly in the past 50 years and it may not be entirely applicable to today's patients. More recently, in 2009, Sihvo et al. performed a retrospective review of all patients with GHH admitted to Finnish hospitals over a 15 -year period. The in-hospital mortality rate for symptomatic GHH patients treated without surgery was $16.4 \%$, or 11 patients out of 67 (15). In total, there were 32 deaths over the 15 years, including 15 patients treated operatively. Three patients died after elective laparoscopic repair, 10 patients after open repair and 2 after thoracoabdominal repair. Of the 32 patients that died, $16(50 \%)$ had type III hernias and in $24(75 \%)$ the cause of death was incarceration. The authors suggest that 
symptomatic patients with GHH should undergo surgery. The caveat of this study is its retrospective nature with selection bias and the heterogeneity of patients and centers.

We offer symptomatic patients with GHH surgery to improve their quality of life and not to prevent a poor outcome. Nonetheless, we are of the opinion that patients with symptomatic type II hernias and patients with crescendo symptom patterns should undergo timely surgery to reduce the risk of incarceration.

\section{Asymptomatic patients}

There is no consensus about the treatment of truly asymptomatic or minimally symptomatic patients with $\mathrm{GHH}$, because we do not have a clear understanding of the natural history of asymptomatic GHH (7).

Two studies, one in 2002 and another in 2018, endeavored to compare watchful waiting versus elective laparoscopic repair using Markov Monte Carlo decision analysis models. These two studies concluded that patients with asymptomatic or minimally symptomatic type II or III paraesophageal hernias would benefit more from watchful waiting $(16,17)$. In 2002, the studies with follow up longer than 5 years were for open operations. An assumption was made that the annual recurrence rate for laparoscopic repair was the same as open. The study in 2018 used a hypothetical cohort were also patients with type II or III hiatal hernias with minimal or no symptoms. Once again, imprecision in the definition of GHH leads to difficulties.

\section{General principles of repair}

Laparoscopic repair of GHH is the current standard of care. The basic tenets of the operation are reduction of hernia sac and herniated contents with extensive mediastinal dissection, obtain at least $2 \mathrm{~cm}$ of intra-abdominal esophagus after reduction, tension-free closure of the hiatus, and fundoplication based on individual patient characteristics. We also include gastric decompression and pleural drainage as important steps in laparoscopic repair of GHH.

\section{Reduction of hernia sac and herniated contents}

We carefully dissect the hiatus circumferentially and leave peritoneal lining covering the crura. The crural peritoneum may reduce the potential for stitches tearing through muscle. Next, we invert and reduce the hernia sac; this step requires extensive mediastinal dissection of the esophagus to the level of the inferior pulmonary veins to provide sufficient intraabdominal esophageal length $(\geq 2 \mathrm{~cm})$. During reduction and mediastinal dissection, it is important to identify and preserve the vagus nerves. However, in case of injury of one or both nerves, we do not recommend any additional intervention unless the patient has problems with clinically relevant postoperative delayed gastric emptying. We allow at least 3 months before making a decision on a pyloric intervention in patients with clinically significant delayed gastric emptying.

\section{Intra-abdominal esophageal length}

A short esophagus (<2 cm intraabdominal esophagus) impedes a tension-free reduction of the hernia and predisposes to recurrence $(18,19)$. Extensive mediastinal dissection is most important step to ensure adequate intraabdominal esophageal length. To determine intra-abdominal length, we identify the top of the gastric folds with intraoperative endoscopy and simultaneous laparoscopic evaluation. We perform a wedge gastroplasty for esophageal lengthening only if after maximal mediastinal dissection the intra-abdominal esophagus is $<2 \mathrm{~cm}$ long (20), regardless of whether we will do a fundoplication or not. We recommend to partially close the hiatus before making a final decision on esophageal length, since the distance of the GEJ to the hiatus is more accurately reflected after partial closure.

\section{Hiatal closure}

We use pledget 0 silk sutures to approximate the crura. Prior to placement of the final 1 or 2 stitches, we advance a 52 French dilator through the GEJ to adequately gauge the final size of the hiatus. We place the final stitch with the dilator in place. In patients with a very large hiatus, we often place an anterior crural stitch if we notice that the right crus are under tension. Insisting on placement of exclusively posterior stitches in a taut right crus may lead to muscle tearing.

The role of mesh in GHH repair is not justified based on the current literature. We do not think permanent mesh should ever be used since it can erode into the esophagus or stomach and lead to severe morbidity (21). There have been several papers in the literature endeavoring to compare mesh versus suture repair of the crura, but most do not have complete data and are retrospective. One clinical trial evaluated the use of biologic mesh in hiatal hernia repair versus no mesh in a prospective fashion, published 
in two papers $(22,23)$. Although results at 6 months were encouraging, the follow-up at 5 years showed no difference in recurrence rates between both groups. On the occasions we encounter right crural tearing, we will make a relaxing incision in the right crus and patch it with Goretex mesh. The medial part of the mesh must not come in direct contact with the esophagus. The authors almost never use mesh, because there is no evidence to support its use and biologic mesh is costly.

\section{The role of fundoplication in repair of a $\mathrm{GHH}$}

The role of fundoplication in these patients is not entirely clear. We know there is a link between GERD and hiatal hernia $(7,24)$, but we don't know if a fundoplication should be performed on every patient with a GHH. The decision regarding whether to perform a fundoplication is nuanced. We generally perform a fundoplication in patients younger than 70 years and in patients with heartburn and regurgitation. There is no data to guide us in deciding whether to fashion a fundoplication in elderly patients and in patients whose main complaint is dysphagia. Additionally, we tend to avoid fundoplication in morbidly obese patients, because hernia recurrence appears to be higher in this population (25). Patients with recurrent hiatal hernia with Nissen fundoplication are often much more symptomatic and more likely to warrant reoperation than patients without fundoplication and hernia recurrence.

\section{Gastric decompression and pleural drainage}

We always use gastric decompression for at least 12 to $24 \mathrm{~h}$ with a nasogastric tube or with a temporary gastrostomy tube that remains in place for at least 4 weeks. In our experience, patients with long-standing $\mathrm{GHH}$ are prone to delayed gastric emptying postoperatively, in particular the elderly. In patients younger than 70 years without major comorbidities we only use nasogastric decompression for about 24 hours. However, in most patients over 70 years, diabetics, and in patients with multiple comorbidities we place a gastrostomy tube. We believe that gastrostomy tubes are safe, prevent massive gastric distension, and possibly may reduce postoperative aspiration. No study has yet addressed whether gastrostomy tubes are beneficial or not after repair of GHH.

The authors routinely place a small bore left chest tube, even if we do not enter the left pleural space during mediastinal dissection. We have observed left pleural effusions that require eventual intervention in patients without tube thoracostomy (with or without entering the pleural space). Usually we remove the chest tube on or after the 2 nd postoperative day. We infrequently place bilateral chest tubes.

\section{Postoperative strategy}

Our patients who undergo GHH repair with a fundoplication are treated according to the postoperative fundoplication principles of gradual diet progression, prevention of postoperative nausea and vomiting, and prevention of constipation. Since the dissection of the GHH is often long and involved, these patients may struggle with postoperative gastric distention. Therefore, we suggest nasogastric decompression for at least 12-24 hours and close monitoring of the gastric bubble with serial $\mathrm{X}$-rays of the chest. In elderly patients, respiratory complications are a key cause for morbidity and even mortality. Elderly patients can be prone to aspiration in addition to gastric distension. In this high-risk population, regardless of the presence or absence of fundoplication, we advocate the use of a temporary gastrostomy tube for decompression which can be removed 4 to 6 weeks later. We believe that the risk and morbidity of a respiratory complication far outweighs the risk and morbidity of a gastrostomy tube. Although we have no data to demonstrate that gastrostomy tubes prevent respiratory complications in this population, we strongly believe they provide an extra tool for the management of these high-risk patients.

\section{Outcomes in GHH repair}

Another controversy in GHH repair is how to evaluate clinical and radiologic results. Patients with symptomatic GHH can expect a 90-95\% improvement in symptoms, including dysphagia, reflux, and regurgitation regardless of surgical approach if treated in a center with surgical expertise $(5,10,26,27)$. Although symptoms are subjective, several studies have used standardized symptom questionnaires in an attempt to reduce variability, including the GERD-HQRL score, QOLRAD, Gastrointestinal Quality of Life Index, Gastrointestinal Symptom Rating Scale and DSS.

Recurrence defies a clear definition. Most reports use reoperation for recurrent symptoms as an obvious clinical recurrence and a re-herniation of $\geq 2 \mathrm{~cm}$ on esophagram as a radiologic recurrence. Table 1 summarizes radiologic and 
Table 1 Recurrence rates in large series

\begin{tabular}{|c|c|c|c|c|c|c|}
\hline Study & $\begin{array}{c}\text { Patients, } \\
n\end{array}$ & $\begin{array}{l}\text { Retrospective }(\mathrm{R}) \text {, } \\
\text { prospective/trial } \\
(\mathrm{P})\end{array}$ & $\begin{array}{c}\text { Type of repair } \\
\text { [thoracotomy }(\mathrm{T}) \text {, } \\
\text { laparoscopy }(\mathrm{L})]\end{array}$ & $\begin{array}{l}\text { Median follow } \\
\text { up (months) }\end{array}$ & $\begin{array}{l}\text { Radiographic } \\
\text { recurrence, \% } \\
\quad(\leq 2 \mathrm{~cm})\end{array}$ & Reoperation, \% \\
\hline Aly et al. (28), 2005 & 100 & $\mathrm{R}$ & L & 47 & $14^{\star}(23.3)$ & $4(4)$ \\
\hline Oelschlager et al. (22), 2011 & 108 & $P$ & L & 58 & $\mathrm{PR}^{\star \star} \mathrm{nr} ; \mathrm{SIS}^{\star \star \star} \mathrm{nr}$ & PR 2 (3.5); SIS 0 (0.0) \\
\hline Chang et al. (27), 2016 & 221 & $\mathrm{R}$ & L & 14 & $2(1 / 0)$ & $1(0.5)$ \\
\hline
\end{tabular}

${ }^{*}$, out of $60 ;{ }^{* *}$, primary diaphragm repair; ${ }^{* \star}$, biologic mesh repair; ${ }^{* \star *}, 15$ out of 445 patients. nr, not recorded.

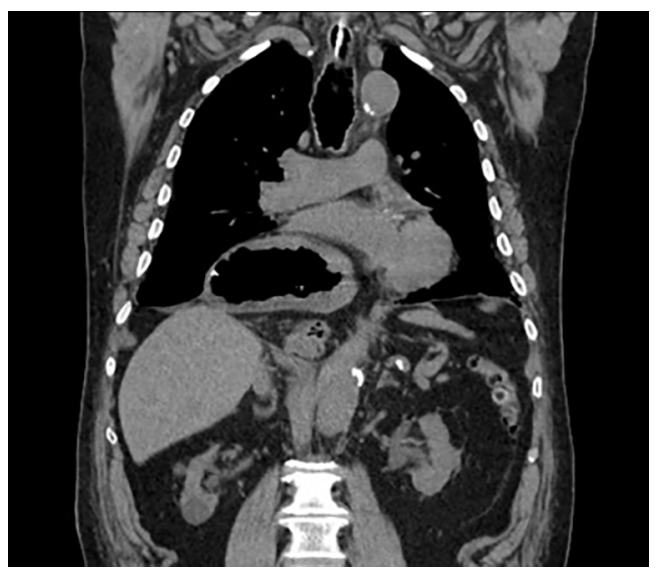

Figure 1 Giant hiatal hernia.

clinical recurrences from the main series published to date.

The remaining challenge is how to define patients with recurrent symptoms that do not mandate reoperation and how to interpret the clinical relevance of a purely radiologic recurrence, and we cannot draw any conclusion from published data.

\section{Role of temporizing measures in patients with incarcerated GHH}

Patients with incarcerated GHH always require an intervention to manage symptoms and prevent strangulation. It is unclear what the proper intervention should be and what optimal timing of the intervention is. Emergent repair of hiatal hernia is associated with higher morbidity and mortality than elective repair, since these patients tend to be older, weaker, weigh less and have more comorbidities than patients who undergo elective repair $(16,29)$. What constitutes the best management of patients with incarcerated GHH? We guide the treatment of these patients primarily by age, comorbidities, and nutritional status.

The first and most important step in patients with incarcerated GHH is to decompress the stomach. Incarcerated $\mathrm{GHH}$ are often difficult or impossible to decompress with a nasogastric tube placed at bedside due to gastric angulation within the chest. A bedside nasogastric tube will either not pass the GEJ or will only decompress a portion of the stomach, while the remainder of the stomach is still dilated (Figure 1). In our experience, endoscopic decompression with fluoroscopic guidance under general anesthesia is the safest and most effective management of an incarcerated GHH.

Once the stomach has been completely decompressed, we decide on further surgical management based primarily on patient characteristics. In low-risk patients with incarcerated $\mathrm{GHH}$, we perform a laparoscopic repair at the time of initial gastric decompression. However, in elderly, frail, and malnourished patients, we use a two-stage approach. First, we decompress the stomach endoscopically with fluoroscopic guidance and place a nasogastric tube over a wire. Second, we decide on the best approach to nutrition and ongoing decompression. Our practice has been to provide intermediate term decompression with a pharyngostomy tube instead of a nasogastric tube, and to place a jejunostomy tube at the time of decompression. We then manage the patient conservatively until nutrition improves, often 10-30 days after decompression. To date, there are no data to guide therapy in this subset of patients, but adhering to the principle of preoperative nutritional optimization seems reasonable. Over an 8-year period, we have treated 9 of 14 patients admitted with an acute, incarcerated, non-strangulated hernia with this temporizing approach. The median age was 72 and all had major 
comorbidities. Despite these preoperative precautions, the morbidity rate was $33 \%$ and the 30 -day mortality rate $11 \%$. In any patient with an incarcerated $\mathrm{GHH}$ and suspicious of strangulation, immediate surgery is imperative.

\section{Redo surgery}

At a tertiary level center in particular, patients who need a redo operation may have undergone their initial procedure at another institution. It is paramount to obtain the preoperative workup, including the history, any testing that was performed and the original operative report. The patient should then undergo a new workup to prepare for the redo operation. In particular, it is important to know the original symptom profile. From the operative report, one can get an idea of how much mediastinal dissection there was, how the crura was repaired, whether the vagus nerves were injured and what sort of fundoplication was performed. It is helpful to know if the vagus nerves will be encountered inside or outside the wrap.

\section{Recommendations for management of GHH}

At this point we can make some recommendations based on what we seemingly understand about GHH. First, a symptomatic GHH warrants consideration of surgical treatment since symptoms will only worsen with time; second, a patient with a GHH and crescendo symptoms requires surgical repair in the short-term because it may portend an incarceration; third, a patient with an incarcerated or strangulated $\mathrm{GHH}$ needs urgent intervention; fourth, patients with type II hiatal hernia, regardless of size, should be treated surgically whenever possible; and, fifth, patients with minimal or no symptoms should be considered for surgical repair, but with limited understanding of the natural history of untreated GHH. As a reflection of these heterogeneous indications for surgery, the SAGES guideline suggests careful evaluation on an individual case basis (7).

\section{Conclusions}

GHH remains a challenging condition. There are still more questions than answers with regard to the management these hernias. Although the past 100 years have seen significant advances in the surgical management of $\mathrm{GHH}$, much work remains to be done.

\section{Acknowledgments}

Funding: None.

\section{Footnote}

Provenance and Peer Review: This article was commissioned by the Guest Editor (Ghulam Abbas) for the series "Minimally Invasive Esophageal Surgery" published in Shanghai Chest. The article has undergone external peer review.

Reporting Checklist: The authors have completed the NARRATIVE REVIEW reporting checklist. Available at http://dx.doi.org/10.21037/shc-20-50

Conflicts of Interest: Both authors have completed the ICMJE uniform disclosure form (available at http://dx.doi. org/10.21037/shc-20-50). The series "Minimally Invasive Esophageal Surgery" was commissioned by the editorial office without any funding or sponsorship. Both authors have no other conflicts of interest to declare.

Ethical Statement: The authors are accountable for all aspects of the work in ensuring that questions related to the accuracy or integrity of any part of the work are appropriately investigated and resolved.

Open Access Statement: This is an Open Access article distributed in accordance with the Creative Commons Attribution-NonCommercial-NoDerivs 4.0 International License (CC BY-NC-ND 4.0), which permits the noncommercial replication and distribution of the article with the strict proviso that no changes or edits are made and the original work is properly cited (including links to both the formal publication through the relevant DOI and the license). See: https://creativecommons.org/licenses/by-nc-nd/4.0/.

\section{References}

1. Stylopoulos N, Rattner DW. The history of hiatal hernia surgery: From Bowditch to loparoscopy. Ann Surg 2005;241:185-93.

2. Nissen R. A simple operation for control of reflux esophagitis. Schweiz Med Wochenschr 1956;86:590-2.

3. Collis JL. An operation for hiatus hernia with short oesophagus. Thorax 1957;12:181-8.

4. Skinner DB, Belsey RH. Surgical management of 
esophageal reflux and hiatus hernia. Long-term results with 1,030 patients. J Thorac Cardiovasc Surg 1967;53:33-54.

5. Maziak DE, Todd TR, Pearson FG. Massive Hiatus Hernia. J Thorac Cardiovasc Surg 1998;115:53-60; discussion 61-2.

6. Johnson AB, Oddsdottir M, Hunter JG. Laparoscopic Collis gastroplasty and Nissen fundoplication. A new technique for. Surg Endosc 1998;12:1055-60.

7. Kohn GP, Price RR, Demeester SR, et al. Guidelines for the management of hiatal hernia. Surg Endosc 2013;27:4409-28.

8. Antonoff MB, D'Cunha J, Andrade RS, et al. Giant paraesophageal hernia repair: Technical pearls. J Thorac Cardiovasc Surg 2012;144:S67-70.

9. Nason KS, Luketich JD, Qureshi I, et al. Laparoscopic repair of giant paraesophageal hernia results in long-term patient satisfaction and a durable repair. J Gastrointest Surg 2008;12:2066-75; discussion 2075-7.

10. Luketich JD, Nason KS, Christie NA, et al. Outcomes after a decade of laparoscopic giant paraesophageal hernia repair. J Thorac Cardiovasc Surg 2010;139:395-404, 404.e1.

11. Sarkaria IS, Latif MJ, Bianco VJ, et al. Early operative outcomes and learning curve of robotic assisted giant paraesophageal hernia repair. Int J Med Robot 2017;13:10.1002/rcs.1730.

12. Ruurda JP, Draaisma WA, van Hillegersberg R, et al. Robot-Assisted Endoscopic Surgery: A Four-Year SingleCenter Experience. Dig Surg 2005;22:313-20.

13. Draaisma WA, Gooszen HG, Consten ECJ, et al. Midterm results of robot-assisted laparoscopic repair of large hiatal hernia: a symptomatic and radiological prospective cohort study. Surg Technol Int 2008;17:165-70.

14. Wirsching A, Klevebro F, Boshier PR, et al. The other explanation for dyspnea: giant paraesophageal hiatal hernia repair routinely improves pulmonary function. Dis Esophagus 2019;32:doz032.

15. Sihvo EI, Salo JA, Räsänen JV, et al. Fatal complications of adult paraesophageal hernia: A population-based study. J Thorac Cardiovasc Surg 2009;137:419-24.

16. Stylopoulos N, Rattner D. Paraesophageal hernia: when to operate? Adv Surg 2003;37:213-29.

17. Jung JJ, Naimark DM, Behman R, et al. Approach to asymptomatic paraesophageal hernia: watchful waiting or elective laparoscopic hernia repair? Surg Endosc 2018;32:864-71.

18. Hashemi M, Peters JH, DeMeester TR, et al. Laparoscopic repair of large type III hiatal hernia:
Objective followup reveals high recurrence rate. J Am Coll Surg 2000;190:553-60.

19. Lin E, Swafford V, Chadalavada R, et al. Disparity between symptomatic and physiologic outcomes following esophageal lengthening procedures for antireflux surgery. J Gastrointest Surg 2004;8:31-9.

20. Whitson BA, Hoang CD, Boettcher AK, et al. Wedge gastroplasty and reinforced crural repair: Important components of laparoscopic giant or recurrent hiatal hernia repair. J Thorac Cardiovasc Surg 2006;132:1196-202.e3.

21. Stadlhuber RJ, Sherif AE, Mittal SK, et al. Mesh complications after prosthetic reinforcement of hiatal closure: A 28-case series. Surg Endosc 2009;23:1219-26.

22. Oelschlager BK, Pellegrini CA, Hunter JG, et al. Biologic prosthesis to prevent recurrence after laparoscopic paraesophageal hernia repair: Long-term follow-up from a multicenter, prospective, randomized trial. J Am Coll Surg 2011;213:461-8.

23. Oelschlager BK, Pellegrini CA, Hunter J, et al. Biologic prosthesis reduces recurrence after laparoscopic paraesophageal hernia repair: a multicenter, prospective, randomized trial. Ann Surg 2006;244:481-90.

24. Fuller CB, Hagen JA, DeMeester TR, et al. The role of fundoplication in the treatment of type II paraesophageal hernia. J Thorac Cardiovasc Surg 1996;111:655-61.

25. Bashir Y, Chonchubhair HN, Duggan SN, et al. Systematic review and meta-analysis on the effect of obesity on recurrence after laparoscopic anti-reflux surgery. Surgeon 2019;17:107-18.

26. Lazar DJ, Birkett DH, Brams DM, et al. Long-term patient-reported outcomes of paraesophageal hernia repair. J Soc Laparoendosc Surg 2017;21:e2017.00052.

27. Chang CG, Thackeray L. Laparoscopic hiatal hernia repair in 221 patients: Outcomes and experience. J Soc Laparoendosc Surg 2016;20:e2015.00104.

28. Aly A, Munt J, Jamieson GG, et al. Laparoscopic repair of large hiatal hernias. Br J Surg 2005;92:648-53.

29. Kaplan JA, Schecter S, Lin MY, et al. Morbidity and Mortality Associated With Elective or Emergency Paraesophageal Hernia Repair. JAMA Surg 2015;150:1094-6.

doi: 10.21037/shc-20-50

Cite this article as: Bhargava A, Andrade R. Laparoscopic repair of giant hiatal hernia: a narrative review. Shanghai Chest $2021 ; 5: 32$. 